\title{
Fertility preferences and contraceptive use among couples in sub-Saharan Africa
}

\author{
Akinrinola Bankole and Suzette Audam \\ Guttmacher Institute, 125 Maiden Lane, $7^{\text {th }}$ Floor, \\ New York NY 10038 \\ abankole@guttmacher.org
}

\section{Abstract}

Fertility remains high and contraceptive use is low in much of sub-Saharan Africa despite high levels of unmet need for contraception and clear evidence of excess fertility. Using data from recent Demographic and Health Surveys this paper revisits the issue of gender differences in fertility goals, and how these differences may contribute to the lack of substantial declines in fertility in the region. The results show that most spouses agreed with respect to their fertility preferences, whether in terms of desired number of children or desire for a future birth. When there were disagreements, men tended to want more children than their spouses. In most countries, contraceptive use among couples was not associated with differences in spouses' desires for a future birth. However, for the few countries where a significant association was observed, couples were less likely to be using a method when the wife wanted to have more children and more likely to be using one when she wanted to stop childbearing. To ensure open and sustained use of contraception within a union, family planning programs must continue to involve men by helping them understand the importance of fewer and well spaced births for the health of women and their children.

\section{Introduction}

The sub-Saharan African fertility regime continues to defy theory and to puzzle demographers and other population experts. While fertility has declined very substantially in other developing regions, it remains high in sub-Saharan Africa. The hope of imminent decline in fertility in the region raised by substantial declines in countries like Ghana, Kenya and Zimbabwe was soon dashed by the stall in that trend at relatively high lev- els. ' While the experience of stalled fertility at an above replacement level is not solely an African phenomenon, what seems unique to this region is that the stall takes place at much higher levels of fertility than is the case in other regions. For example, a 2006 study shows that Bangladesh, Colombia, Dominican Republic, Ghana, Kenya, Peru, and Turkey experienced fertility decline to fewer than five births per woman in the early or mid-1990s, before stalling. ${ }^{2}$

I. Central Statistical Office (CSO) and Macro International Inc. 2007. Zimbabwe Demographic and Health Survey 2005-06. Calverton, Maryland: CSO and Macro International Inc.; Kenya National Bureau of Statistics (KNBS) and ICF Macro. 2010. Kenya Demographic and Health Survey 2008-09. Calverton, Maryland: KNBS and ICF Macro; Garenne, M. 2008. Situation of fertility stall in sub-Saharan Africa, African Population Studies, 23(2): 173-188. 
However, the level at which the stall occurred varied, ranging from 4.7 births per woman in Kenya to 2.5 births per woman in Turkey. In the countries outside of sub-Saharan Africa, including Bangladesh, Dominican Republic, Egypt and Indonesia, fertility stalled at about 3 children per woman compared to more than 4 children per woman in Ghana and Kenya and about 4 in Zimbabwe ${ }^{3}$.

Despite the generally high fertility and lack of significant progress in the pace of fertility transition in sub-Saharan Africa, evidence shows that demand for smaller family size is increasing and many couples are having more children than they want. This is evident from the high levels of unmet need and unplanned pregnancies and births. For example, among the developing regions, only in sub-Saharan Africa is the proportion of married women with unmet need higher than one in five. ${ }^{4}$ Similarly, while fairly substantial declines were observed in unmet need between the mid-1990s and early 2000s in Latin America (17\% versus 12\%), North Africa and West Asia (14\% versus 10\%) and South and Southeast Asia (18\%$11 \%)$, there was little or no decline in unmet need in sub-Saharan Africa $(26 \%$ versus $24 \%){ }^{5}$ The proportion of married women who want to stop childbearing has increased substantially in many of the sub-Saharan countries. For example, the proportion increased from $23 \%$ in 1988 to $36 \%$ in 2008 in Ghana and from $24 \%$ in 1992 to $36 \%$ in 2007 in Zambia. ${ }^{6}$ Similarly, in Cameroon, this proportion increased from $14 \%$ in 1991 to $21 \%$ in 2004 , while in Uganda it increased from $19 \%$ in 1988 to $41 \%$ in $2006 .{ }^{7}$ However, because of the low use of contraception in many of these countries, the number of children couples are having is higher than the number they want to have.

Spousal differences in fertility preferences and disposition towards contraceptive use have been advanced as a major reason for this disjunction between desired and actual fertility in sub-Saharan Africa. Studies, many undertaken in the 1990s, have shown that men tend to desire more children than women in the region and that real

2. Bongaarts, J. 2006. The Causes of Stalling Fertility Transitions, Studies in Family Planning, $37(I) 1-16$.

3. Bongaarts, J. 2008. Fertility Transitions in Developing Countries: Progress or Stagnation? Working Paper, No 7, The Population Council: New York

4. Sedgh, G., R. Hussain, A. Bankole, and S. Singh. 2007. Women with an unmet need for contraception in developing countries and their reasons for not using a method, Occasional Report, New York: Guttmacher Institute, No. 37.

5. Sedgh, G. et al. 2007 (see reference 4).

6. Ghana Statistical Service (GSS) and Institute for Resource Development/Macro Systems, Inc. 1989. Ghana Demographic and Health Survey 1988. Columbia, Maryland: GSS and IRD/Macro Systems, Inc.; Ghana Statistical Service (GSS), Ghana Health Service (GHS), and ICF Macro. 2009. Ghana Demographic and Health Survey 2008. Accra, Ghana: GSS, GHS, and ICF Macro; University of Zambia, Central Statistical Office and Macro International Inc. 1993. Zambia Demographic and Health Survey 1992. Columbia, Maryland: Macro International Inc. Central Statistical Office (CSO), Ministry of Health $(\mathrm{MOH})$, Tropical Diseases Research Centre (TDRC), University of Zambia and Macro International Inc. 2009. Zambia Demographic and Health Survey 2007.Calverton, Maryland, USA: CSO and Macro International Inc. 
or perceived knowledge of a husband's opposition to family planning may prevent a woman from using a method even when she wants to stop childbearing. ${ }^{8}$ A 1999 study examined the implication of gaps in the fertility preferences of women and men for unmet need for contraception by taking into account husbands' preferences in estimating unmet need. 9 The study showed that when husbands' preferences are accounted for, the level of unmet need drops substantially from what it is when only wives' preferences are taken into consideration. The study concluded that unless we take men's fertility preferences into account in assessing fertility and contraceptive outcome, there will always be gaps between observed and expected behaviors based on information from women alone.

While there is a consensus that women bear the greater burden of childbearing and childrearing, it is also acknowledged that childbearing and childrearing impact on men's lives too. This impact can be felt financially if men accept the responsibility of supporting their children, and in a range of other ways, including the health and wellbeing of their wife and children. ${ }^{10}$ The male partner may also play an important role in decision-making regarding contraceptive use and the timing and number of births the couple will have. In some countries or among some social groups, the influence of a male partner may be greater than that of his spouse. "I In Ghana, one study found that the wife's attitude to contraception is strongly influenced by her husband's attitudes and background characteristics, especially education, but the reverse is not true. ${ }^{12}$

In a study among the Yoruba of

7. Direction Nationale du Deuxième Recensement Général de la Population et de l'Habitat and Macro International Inc. 1992. Enquête Démographique et de Santé Cameroun 1991, Columbia, Maryland: Macro International Inc.; Institut National de la Statistique (INS) et ORC Macro. 2004. Enquête Démographique et de Santé du Cameroun 2004.Calverton, Maryland, USA : INS et ORC Macro; Ministry of Health, Ministry of Planning and Economic Development, Makerere University and Institute for Resource Development/ Macro Systems, Inc. 1989. Uganda Demographic and Health Survey 1988/1989. Columbia, Maryland: IRD/Macro System, Inc.; Uganda Bureau of Statistics (UBOS) and Macro International Inc. 2007. Uganda Demographic and Health Survey 2006. Calverton, Maryland, USA: UBOS and Macro International Inc.

8. Casterline, J.B., A.E. Perez, and A.E. Biddlecom. 1997. Factors underlying unmeet need in the Philippines. Studies in Family Planning 28(3): 173-191; Gebreselassie, T. and M. Vinod.2007. Spousal Agreement on Family Planning in Sub-Saharan Africa. DHS Analytical Studies No. I I. Calverton, Maryland: Macro International.

9. Bankole, A. and A.C. Ezeh. 1999. Unmet need for couples: an analytical framework and evaluation with DHS data, Population Research and Policy Review, 18(6):579-605.

10. Frank, O. and G. McNicoll. 1987. An Interpretation of Fertility and Population Policy in Kenya, Population and Development Review, , 13(2):209-243; Fapohunda, E.R. and M.P. Todaro. 1988. Family Structure, Implicit Contracts, and the Demand for Children in Southern Nigeria, Population and Development Review, I4(4):57I-594.

II. Lasee, A. and S. Becker. 1997. Husband-Wife Communication About Family Planning and Contraceptive Use in Kenya, International Family Planning Perspectives 23(I):I5-20; Casterline, J.B. et

12. Ezeh, A. C. 1993. The Influence of Spouses over each other's contraceptive use in developing countries. International Family Planning Perspectives. 26(3): 100-109. 
Nigeria, it was shown that the fertility desires of marital partners are important predictors of the couple's fertility. However, the relative importance of spouses' desires is associated with the number of living children. When the number is small, the husband's desire is dominant in predicting the couple's behavior. On the other hand, the wife's desire becomes more important during the later stages of childbearing. ${ }^{13} \mathrm{~A}$ study in Sudan found that the decision not to use contraception is made by men, and when a couple is contracepting it is the husband who provides the method. ${ }^{14}$ It is in light of this that some researchers question the validity of the estimates of unmet need derived from information collected only from women. ${ }^{15}$

This paper examines the reproductive preferences and behavior of married men and their wives in 24 countries in sub-Saharan Africa. It undertakes a comparative analysis of the fertility preferences and contraceptive behavior among marital partners using recent data from the Demographic and Health Survey (DHS). The focus of the study is to understand how women's reproductive aspirations and actual behavior compare with those of their husbands. To achieve this goal, we compare the responses of husbands with those of their wives. Specifically, we explore the similarities and differences in their family size preferences, actual fertility and current use of modern contraceptives. When there is a disagreement about fertility desires, we attempt to identify which of the spouses' desires has greater influence if any, on a couple's use of modern contraceptives. The findings provide important information for policy makers and programmers to address the persistent high fertility in sub-Saharan Africa taking into account gender differences in fertility aspirations and household power dynamics.

\section{Data sources and methods of analysis}

Data sources: The data used for this study are from national surveys of men and women conducted by Macro International Inc. in collaboration with incountry agencies and organizations between 2003 and 2009 in 24 countries of sub-Saharan Africa. These data are valuable because they come from the only major series of cross-national surveys of reproductive behavior and health in developing countries that include both men and women. To obtain the couple data used in this study we combined data from the separate interviews of men and women. The list of the countries included in this study and the size of the nationally representative samples of couples in the 24 countries are shown in Table I.

13. Bankole, A. 1995. Desired fertility and fertility behaviour among the Yoruba of Nigeria: a study of couple preferences and subsequent fertility, Population Studies, 1995, 49(3):317328.

14. Khalifa, M.A. 1988. Attitudes of Urban Sudanese Men Toward Family Planning, Studies in Family Planning, 19(4):236-243.

15. Dodoo, F.N-A. 1993. Couple Analysis of Micro Level Supply/Demand Factors in Fertility Regulation, Population Research and Policy Review, 12(2):93-101; Bankole, A. and A.C. Ezeh .1996. Unmet Need for Couples: A Conceptual Framework and Evaluation with DHS Data, paper Presented at the annual meeting of the Population Association of America, Washington, DC, March 26-29, 1996. 


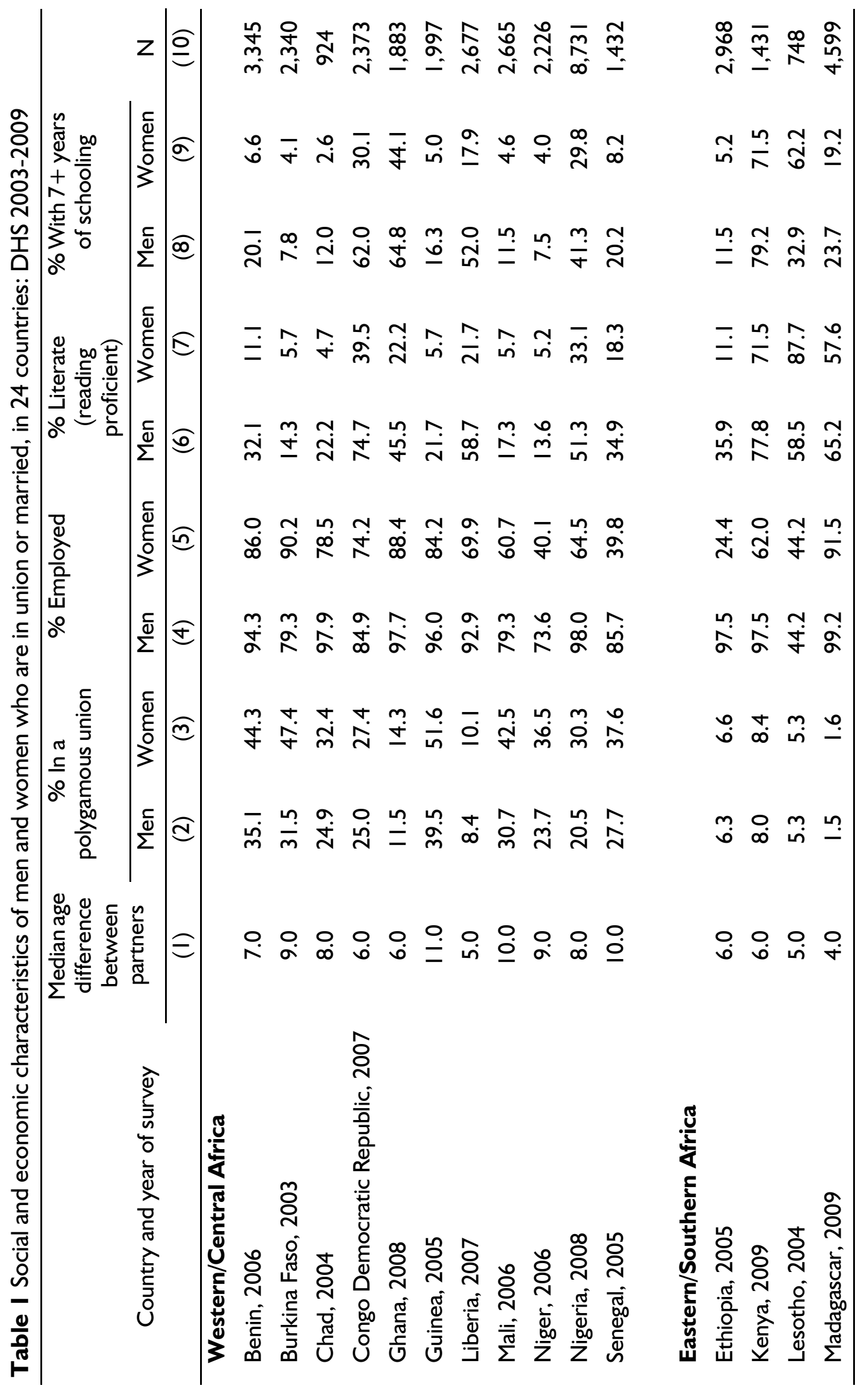




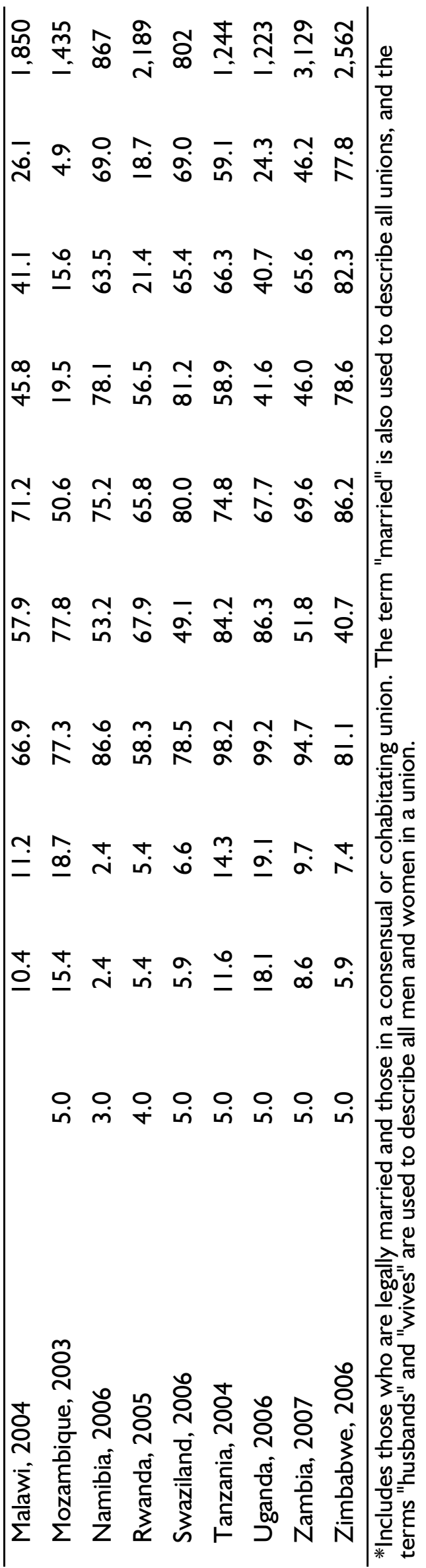

The structure of the male questionnaire is quite similar to that of the female questionnaire, although the former is shorter. With the exception of the birth history, child health and anthropometry sections, which are absent in the male questionnaires, all other standard sections in the female questionnaire are also available in the male questionnaire. Men are asked questions about their background characteristics, fertility experiences, contraceptive knowledge and use, marriage and sexual behavior and reproductive preferences. The fertility section includes detailed questions on number of children ever born and number of surviving and deceased children by sex. In some of the earlier surveys men were only asked, through a single question, to tell the number of own children or number of living children by sex. In the section on contraception, all modern and traditional methods are listed and any other (folkloric) methods mentioned are recorded. First, the respondent is asked whether he knows any method: this allows the respondent to spontaneously list methods that he knows. Subsequently, the interviewer reads a description of each method that was not mentioned and asks the respondent whether he/she knows any of these. The respondent is later asked if he has ever used each one of the methods that he/she said he had heard of. Also, detailed questions are asked about current use of methods as well as intention to use among non-users.

In the section on fertility preferences male respondents are asked questions on a wide range of issues touching on fertility and contraception. These include questions about their 
ideal number of children (in some cases by sex), whether they intend to have any more children and, if so, the preferred timing of the births, and their own as well as their partners' (where applicable) attitudes toward family planning. As much as possible, particularly for the standard modules, the questions in the male questionnaire are worded the same way as in the female questionnaire. This article focuses on data from the sections on contraceptive knowledge and use and fertility preferences of both male and female surveys.

Method of analysis: We adopt the DHS definition of a couple as consisting of a man and a woman who are legally married to each other or who are living together in a consensual or cohabiting union. In those countries where polygyny is widely practiced, this implies that the sample of couples includes cases in which a man has more than one wife. In that situation, for our analysis, the polygynous household is counted as having as many couples as the number of wives, and the information for the male spouse is the same for each of these couple units. However, a special problem arises for these couples. Most of the questions asked of husbands that relate to their wives did not require a polygynous man to be wife-specific in answering the questions. Therefore, we do not know to which wife or wives such responses by a polygynous husband refer. Unfortunately, there is nothing that can be done to correct this problem. Thus, in cases where this point really matters, we either carry out the analysis by type of marriage or include monogamous couples only. The presentation of the findings focuses on the results for the whole sample of cou- ples and draws out differences by marriage type when they exist. We define a couple as polygynous or monogamous based on the response of the husband to the question about the number of wives that he has.

To examine the ideal number of children, knowledge of contraceptives and use of modern methods among couples, we constructed measures of these variables combining husbands' and wives' reporting. For instance, the measure of use of modern methods of family planning reported in Columns 4 through 6 of Table 5 is a three-category variable based on information for both partners. It shows the proportions of couples in which only the husband reports use, both spouses report use, or only the wife reports use. Using this measure we are able to show the level of agreement between spouses with respect to use of modern methods of family planning. At the same time, this approach allows us to measure the use of modern methods separately for both husbands and wives. For husbands, it is the sum of the proportion of couples in which both spouses report use of modern methods (Column 5) and the proportion of couples in which only the husband reports use of modern methods (Column 4). Similarly, for wives, it is the sum of the proportion of couples in which both spouses report use of modern methods (Column 5) and the proportion of couples in which only the wife reports use of modern methods (Column 6). Thus, while our analysis focuses primarily on within couple variations, we also take into account differences between husbands and wives.

The analysis of the effects of fertility intentions on contraceptive behavior of 
couples is restricted to fecund monogamous couples who are not currently pregnant. Polygynous couples are excluded because it is unknown which of the wives the husband has in mind in answering the question about fertility intentions. Couples are considered fecund if neither of the spouses declares himself/herself or their partner infecund. A couple is defined as using a modern method of family planning if the wife reports current use of any method. However, if the wife does not report use of a method and the husband reports use of condoms, the couple is also considered as using a modern method. ${ }^{16}$ Two logistic regression models were estimated: the first shows the effects of fertility intentions on the use of modern contraceptives without controlling for any other variable, while the second controls for the effects of age and education of spouses, rural-urban residence (not available in Malawi) and number of living children. The results of both models were converted into predicted proportions (unadjusted and adjusted respectively). This approach is preferred to reporting the odds ratios because it affords a clear and easy comparison of the effects of joint fertility intentions on the use of modern contraception before and after controlling for the effects of other variables. ${ }^{17}$

The procedure involves adding the constant to the parameter estimate for each of the four categories of joint fertility intentions and computing the antilog. Using Ghana as example, to calculate the unadjusted proportions, we first run a logistic regression of use of modern method on joint fertility intentions with no control. Then we obtain the predicted logits for the four categories by adding the constant value $(-I .34327 I)$ to the parameter estimates $(0.6466713,0.416414,0.0883594$ and $0.0)$. The results, ordered to correspond to the categories in Columns 2 through 5 of Table 6, are: -0.6965997 , 0.926857, -1.2549116 and $-1.34327 I$. Taking the antilog of each of these numbers and dividing by I plus the antilog produces the reported results in Table 6. For instance, the $28.4 \%$ in Column 2 is obtained as follows: EXP($0.6965997)$ divided by (I+EXP($0.6965997)$ times 100 equals 28.4 . The weighted average of these predicted proportions, computed using the sample weights $(25.0 \%$ in Column I) yields the same result as the overall proportion using modern methods of family planning obtained from a simple cross tabulation of joint fertility intentions by use of modern methods. The adjusted proportions are obtained, similarly, from the results of the logistic regression of the use of modern methods on joint fertility intentions and all the control variables. But these proportions have been scaled to reproduce exactly the sample total so that the overall proportions of couples using contraception is the same for the unadjusted and adjusted numbers. This involves changing only the regression constant and is done by solving for a constant value that will produce the desired overall proportion.

16. We include the husband's report of condom use because women may under-report use of male methods, especially the condom.

17. Westoff, C.F. and G. Rodriguez. 1994. The Mass Media and Family Planning in Kenya, DHS Working Papers, Columbia, MD, USA: Macro International, No. 4. 
Data limitations: The data are limited to the extent that large-scale national surveys, like the DHS, usually involve the use of structured interviews that do not probe deeply into most topics and usually will not include openended questions. As noted earlier, polygynous men were not asked the questions about future fertility preferences and current contraceptive use with respect to specific wives. Since it is possible for the responses to differ when considered with respect to each wife, it seems inappropriate to treat them as applicable to all of the man's wives. These limitations restrict deeper coverage on some of the issues examined here. For example, we have to restrict the multivariate analysis to monogamous couples only. Furthermore, the lack of uniformity in the ages of male respondents leads to some bias in overall comparisons. While the respondents' age range for the male surveys is 15-59 for most of the countries, including Burkina Faso, Democratic Republic of Congo, Ghana, Ethiopia, Madagascar, Nigeria and Rwanda, it is 15-54 for Kenya, Malawi and Zimbabwe and 15-49 for Liberia and Tanzania. Nevertheless, because of the rare nature of the DHS data, comparing results across the 24 countries is a worthwhile exercise that may help our understanding of reproductive preferences and decision-making among couples.

\section{Results}

Background characteristics of husbands and wives

Column I of Table I shows the median age difference between husbands and wives. ${ }^{18}$ In all countries, the husband is older than the wife with the lowest median age difference of 3.0 in Namibia and the highest difference of 11.0 in Guinea. In general, the gap between the ages of husband and wife tends to be wider for countries in Western and Central Africa than for countries in the Eastern and Southern sub-region. In some settings, the difference in the ages of husband and wife has been found to be a determinant of whether or not the couple will have similar reproductive preferences. 19

The practice of polygyny is still prevalent in sub-Saharan Africa, although wide variations exist in the level of polygyny between countries. It is more prevalent in Western and Central sub-regions, where $8-40 \%$ of men and $10-52 \%$ of women reported that they were in a polygynous union. This is in sharp contrast to Eastern and Southern Africa where 2-18\% of men and 2-19\% of women were polygynously married. The reason for the higher incidence of polygyny in Western Africa includes the greater practice of the Islamic religion in that sub-region, particularly in countries such as Senegal, Burkina Faso and Niger. The difference in the prevalence of polygyny may account for the larger age gap between spouses observed for these countries, since women in more

18. The information in this table is not repeated for men who have more than one wives in the sample, therefore, the number of cases are different for men and women.

19. Bankole, A. and D.O. Olaleye. 1995. Do Marital Partners Have Different Reproductive Preferences in sub-Saharan Africa?," in Makinwa, P. and A. Jensen, eds., Women's Position and Demographic Change in Sub-Saharan Africa, Liege, Belgium: IUSSP, I995, I47-I67. 
polygynous societies tend to marry at younger ages than their counterparts in less polygynous societies. ${ }^{20}$

In 22 of the 24 countries, the vast majority of the husbands were currently working, with at least 2 out of 3 husbands reportedly employed at the time of the survey (Table I Column 4). Only in Rwanda and Lesotho is this proportion lower than $66 \%(58 \%$ in Rwanda and $44 \%$ in Lesotho). A substantial proportion of the wives were also working at the time of the survey, although the variation between countries is larger for wives than for husbands. At least $66 \%$ of wives were currently working in 12 out of the 24 countries (Table I Column 5). Much lower proportions of wives working (24-40\%) are found in Ethiopia, Niger and Senegal. Generally, the proportion of women who were working is somewhat higher in Western and Central Africa than in the Eastern and Southern parts.

Education is another widely acknowledged determinant of reproductive preferences and behavior. We examine this characteristic for husbands and wives using two indicators: percentage literate and years of schooling. The lowest literacy rate of $14 \%$ is found among husbands in Niger and Burkina Faso, while the highest rate of $86 \%$ is among husbands in Zimbabwe (Table I Column 6). The proportion of husbands who were able to read is $50 \%$ or more in almost half of the 24 countries. The level of literacy among wives is considerably lower than that of their husbands in all but three countries in the south. The proportion of wives who can read without difficulty ranges from $5 \%$ in Niger to $88 \%$ in Lesotho. Only in 8 countries, all from Eastern and Southern sub-regions, is this proportion is $50 \%$ or more. In II of the 24 countries, mostly those in Western and Central parts of the region, the proportions literate among husbands are at least two times those for wives. On the contrary, literacy rates among women in Lesotho, Namibia and Swaziland, all in the south, exceed rates among their husbands, $78-88$ compared to $59-75 \%$. In terms of years of schooling, level of education is still unacceptably low in many sub-Saharan countries. The lowest proportion of husbands with 7 or more years of schooling is found in Niger and Burkina Faso (8\%) and the highest is in Zimbabwe (82\%). In 15 of the 24 countries, less than $50 \%$ of husbands have less than 7 years of education. Wives tend to spend fewer years in school than their husbands in most of these countries. The proportion of wives with 7 or more years of education is less than $20 \%$ in 12 of the countries and exceeds $50 \%$ in only 6 countries, all of which are in Eastern and Southern Africa (Column 9). Thus, educational attainment is lower in Western and Central Africa than in the Eastern and Southern parts and lower among wives than their husbands.

\section{Childbearing aspirations and actual behavior}

Unlike about a decade ago, we now know more about the childbearing preferences of men, and how it compares to those of women. A review of very early studies suggests that married men do not seem to desire more chil-

20. Westoff, C.F., A.K. Blanc and L. Nyblade. 1994. Marriage and Entry into Parenthood, DHS Comparative Studies, Calverton, MD, USA: Macro International, 1994, No. 10. 
dren than their wives in developing countries. ${ }^{21}$ Another study using DHS data concluded that with the exception of some countries in West Africa, the family size preferences of men and women are quite similar. ${ }^{22}$ However, this conclusion was based on aggregate level results which may conceal disagreements at the level of couples. Now that we have data from several countries, there is a need to further examine this issue. A study among 14 sub-Saharan African countries with DHS data conducted between 1999 and 2004 found that both in terms of the ideal number of children and whether or not spouses want more children, husbands tend to be more pronatalist than their wives. ${ }^{23}$ There is more to learn from it, especially at this time when fertility is stalling at high levels in the region. Is it the case that men desire a similar number of children to their partners? If not, how large is the difference and has the gap increased, decreased or remained constant over time?

Desired number of children. One measure of reproductive preference that is commonly obtained from fertility surveys is the number of children that a respondent would like to have if he/she could choose. Columns I through 3 of Table 2 present evidence of differences in the number of children desired by matched pairs of husbands and wives. ${ }^{24}$ It is clear from the results that husbands tend to want a larger family size than their wives in many of the countries represented in this study. The proportion of couples in which the husband desires more children than his wife ranges from $25 \%$ in Rwanda to $64 \%$ in Guinea (Column I). This proportion is $40 \%$ or more in 20 of the 24 countries. In addition to Rwanda, the other countries where it is less than $40 \%$ are Madagascar, Malawi, and Tanzania. The corresponding estimate for a wife wanting more children than her husband ranges from $19 \%$ in Guinea to $42 \%$ in Rwanda, the only country where the proportion is $40 \%$ or more (Column 2).

If we consider a situation in which husband and wife reported the same desired number of children (i.e. where they are in agreement with respect to their ideal number of children), the results indicate that agreement is very low among couples in sub-Saharan Africa. The proportion of couples in which spouses agree with respect to their desired number of children ranges from $15 \%$ in Chad to only $37 \%$ in Madagascar (Column 3). The only other countries, all in Eastern and Southern sub-regions, where this proportion is $30 \%$ or higher are Kenya, Malawi,

2I. Mason, K.O. and A.M. Taj . 1987. Differences between women's and men's reproductive goals in developing countries, Population and Development Review, I3(4):6 I I-638.

22. Ezeh, A.C., M. Seroussi and H. Raggers. 1996. Men's Fertility, Contraceptive Use, and Reproductive Preferences, DHS Comparative Studies, Calverton, MD, USA: Macro International, No. 18.

23. Gebreselassie, T. 2008. Spousal Agreement on Reproductive Preferences in Sub-Saharan Africa. Calverton, Maryland, USA: Macro International Inc.

24. The DHS question from which the measure was derived asks nulliparous respondent: "If you could choose exactly the number of children you have in your whole life, how many would that be?" For those who already have at least one child the question was prefaced by: "If you could go back to the time you did not have any children ..." Responses that are not given in the form of a specific number, but that imply that whatever comes will be accepted (up to God; as many as Allah sends; etc) are assigned the value of 6 children for both husbands and wives. 
African Population Studies Vol 25, 2 (Dec 20II)

Rwanda and Lesotho.

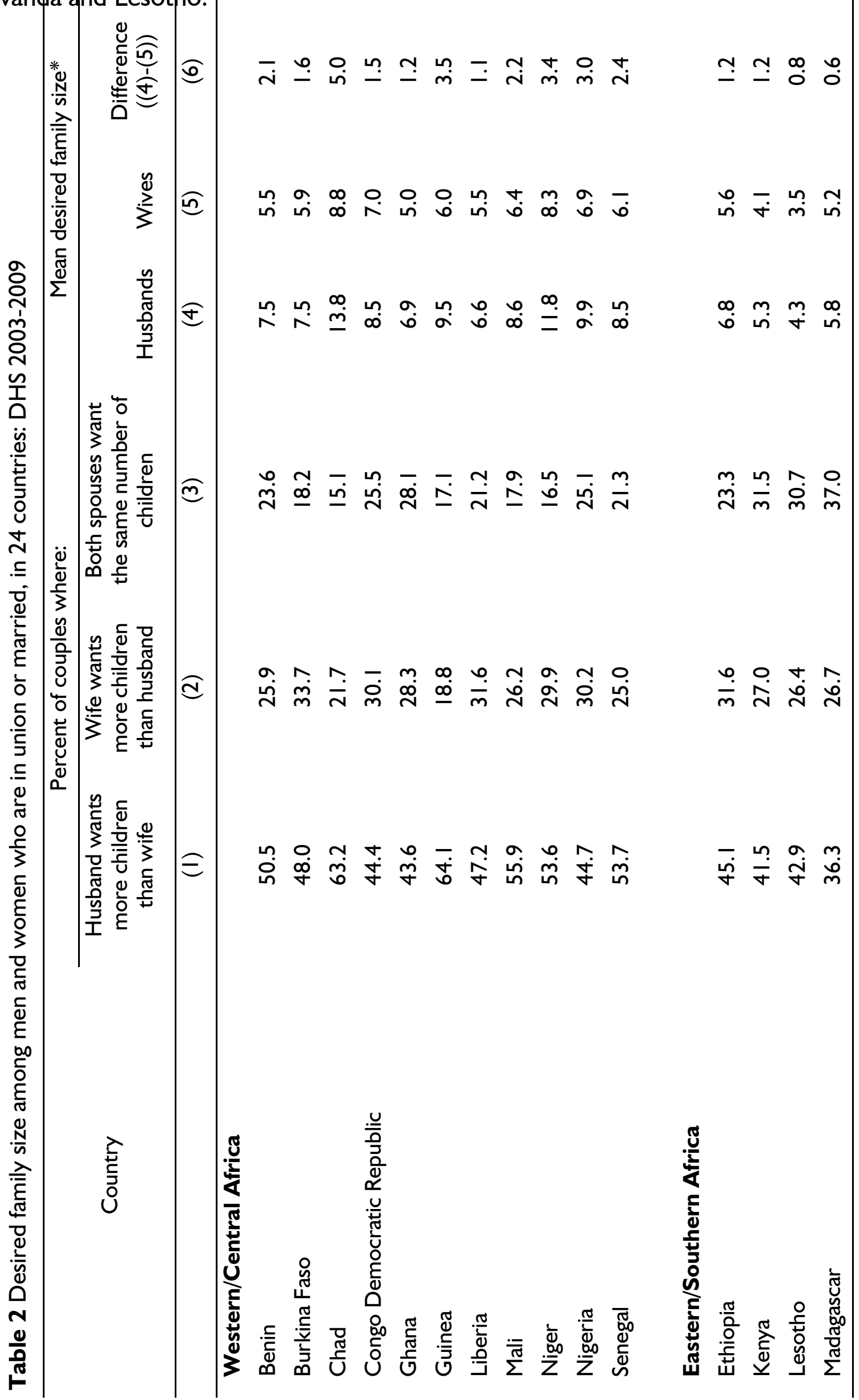




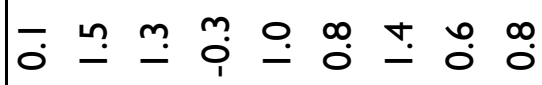

$\underset{\forall}{\forall}$ นก

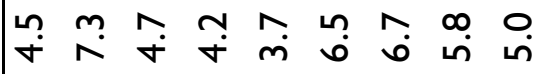

离

萑

$0 . \div$.

ஸ்

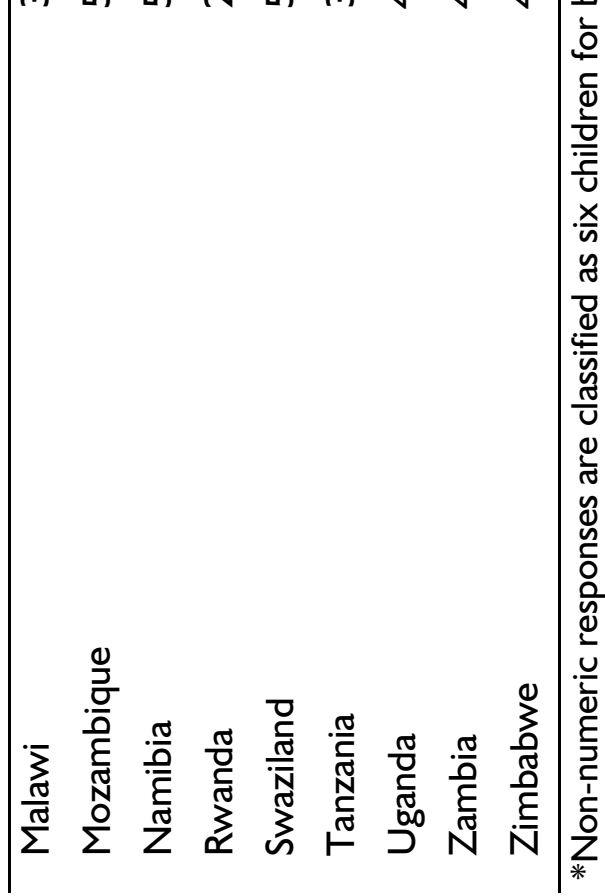

On average, married men still want a large number of children in many of the 24 countries included in this study (Table 2 Column 4). The mean the number of children desired by husbands ranges from 3.7 in Swaziland to 13.8 in Chad. The mean desired number of children among husbands exceeds 5 in 18 of the 24 countries. Desired family size tends to be higher among husbands in Western and Central African countries relative to their counterparts in the countries of Eastern and Southern Africa. Among wives, the average number of children desired ranges from 2.7 in Swaziland to 8.8 in Chad (Column 5). The average family size preferred by wives is more than 5.0 in 16 of the 24 countries.

These results support the claim that husbands tend to want larger families than their wives. If a difference in mean desired family size of one child or more is considered substantial, the contention that men want more children than women is clearly evident in Western and Central Africa (Table 2 Column 6). The countries in Eastern and Southern Africa that show a sign of gender differential based on this criterion are Ethiopia, Mozambique, Uganda, Namibia and Swaziland. This differential desire for children does not seem to be associated with whether men and women are in a polygynous or monogamous relationship. The proportion in which marital partners want the same number of children among monogamous couples is similar to what is observed among all couples. For example, this proportion among monogamous couples is $16 \%$ in Chad, $26 \%$ in Uganda and Zimbabwe, $31 \%$ in Ghana and Lesotho and $37 \%$ in Madagascar (data not shown). 
Fertility Intentions. Another prominent measure of reproductive preferences considered in this study is future fertility desire or fertility intentions, i.e. whether or not the respondent desires or intends to have more children. Because it points to future behavior, the predictive validity of the measure is of great interest and potential utility. Both at the aggregate and individual (or couple) levels it has been found to be a robust predictor of subsequent contraceptive and fertility behavior. ${ }^{25}$ In addition, the measure has become an indispensable information for estimation of unmet needs for family planning. ${ }^{26}$

Comparing husbands' and wives' responses on this issue among all couples using DHS data is somewhat problematic. To do this with little or no bias requires that we have specific responses from polygynous husbands about each of their wives. These are not available in these DHS data; rather the man was simply asked his future intentions. The implication for our study is that the lack of wife-specific responses is likely to understate the degree of agreement between spouses in polygynous unions. For example, if a man with two wives wants no more children, it is safe to assume that his response applies to both wives, therefore, the agreement or disagreement between him and any of the wives is not in question. On the other hand, if he wants more children, this may mean either of two things: he wants more with both wives or he wants more with one (probably the younger) wife. If he wants more with both wives, again the implied agreement or disagreement with the wives is real. But if he wants more children say with only the younger wife, more often the older wife too would want no more children, given that wives tend to want fewer children than their husbands. This agreement will be misconstrued as a disagreement due to the fact that the husband has only one response choice. Because of this problem, doing this analysis among all couples may overstate the amount of disagreement between spouses. To examine how true this may be we did the analysis among all couples as well as among monogamous couples to see whether there is any difference in the results for the two groups.

25. Bongaarts J. 199I. Do Reproductive Intentions Matter?, Working Papers, New York: Population Council, 199I, No. 30; Thomson, E., E. McDonald and L.L. Bumpass. 1993. Fertility Desires and Fertility. Hers, His and Theirs, Demography, 27(4):579-588.

26. Westoff, C.F. and L.H. Ochoa . 199I. Unmet Need and the Demand for Family Planning, DHS Comparative Studies, Columbia, MD, USA: Institute for Resource Development/ Macro International, , No. 5; Westoff, C.F. and A. Bankole. 1995. Unmet Need: 19901994, DHS Comparative Studies, Calverton, MD, USA: Macro International, , No. 16. 


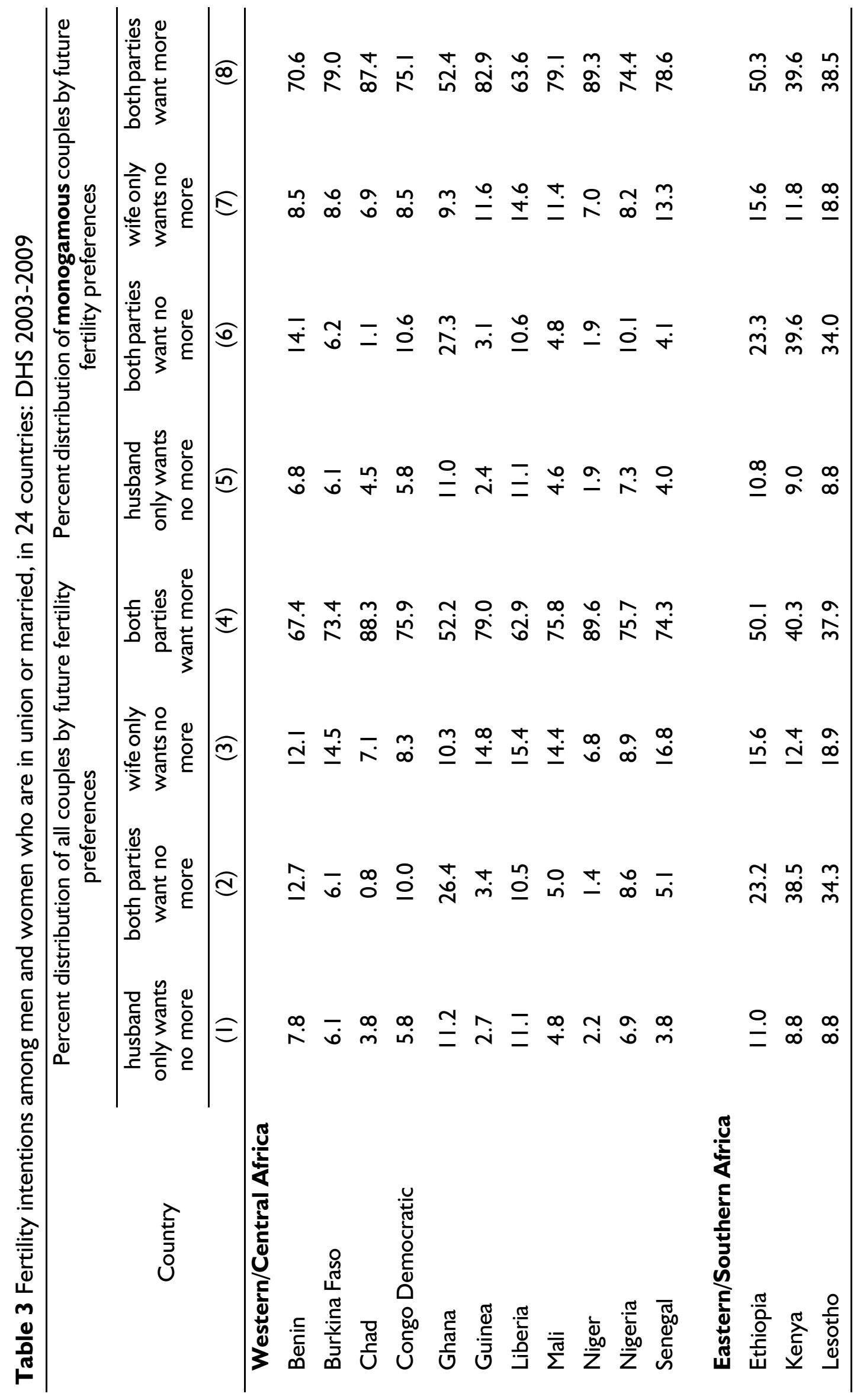




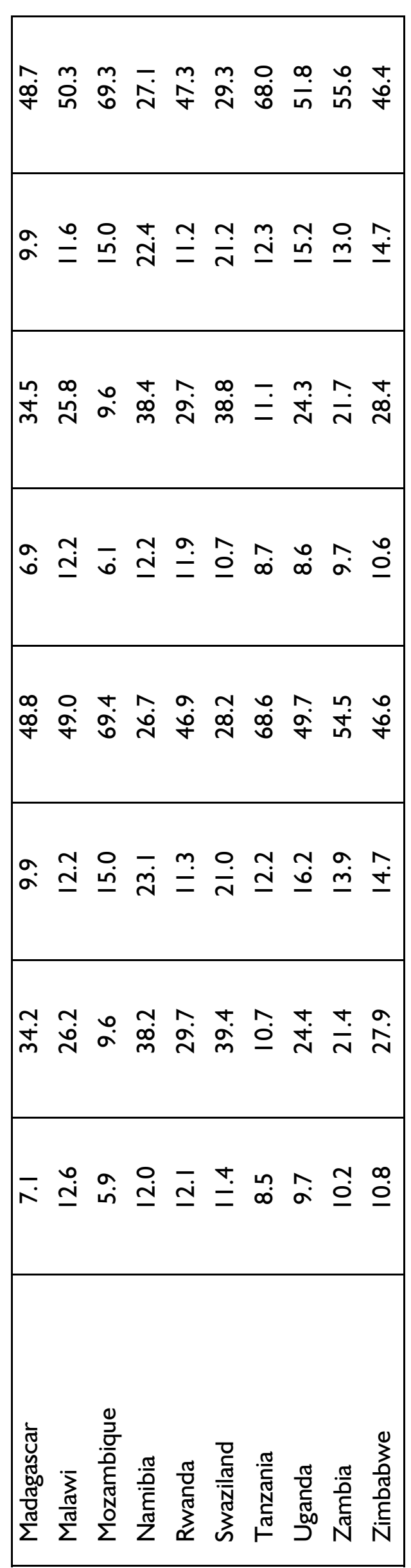

Columns I through 4 of Table 3 present the joint distribution of the fertility desires of husbands and wives among all couples. ${ }^{27}$ Despite the possibility of bias in the direction of disagreement, the results show a high degree of agreement between husbands and wives about their fertility intentions (the sum of Columns 2 and 4). The percentage of couples in which both spouses agree (either to want more or no more children) ranges from $72 \%$ in Lesotho to $91 \%$ in Niger. In general overall agreement tends to be higher among countries in Western and Central African compared to countries in Eastern and Southern parts of the region.

As noted above, agreement is of two types: it is either that both spouses want no more children (Column 2) or both want more children (Column 4). In all of the countries, with the exception of Namibia and Swaziland, agreement between husband and wife with respect to their fertility preferences is more of the second type - both want more children. Of all couples in agreement, the percentage that agreed to have more children ranges from $41 \%$ in

27. In both men and women surveys the question about the future fertility intentions is asked in DHS as follows: "Now, I have some questions about the future. Would you like to have a/another child or would you prefer not to have any (more) children?" For the purpose of the analysis presented in Columns 5 through 8 , we exclude all couples who declared themselves infecund. For the remaining couples, husbands or wives who were not certain about their fertility intentions were classified as wanting to have more children. 
Namibia to $98 \%$ in Niger. ${ }^{28}$ This supports the earlier finding that a high proportion of both husbands and wives want a large family in sub-Saharan Africa. Couples in the countries of Western and Central Africa tend to be more likely to agree to have more children than their counterparts in eastern and Southern Africa. While the proportion of couples in agreement that they both want more children is $69-99 \%$ in Western and Central sub-regions, that same proportion is $41-88 \%$ in Eastern and Southern Africa. This difference by sub-region is not surprising since desired family size and actual fertility are generally lower in the latter subregions than the former.

Since $100 \%$ agreement is not achieved by couples in any country considered in this study, it is clear that in all settings, some couples will experience and must manage disagreement on this issue. Two types of spousal disagreement on fertility intentions are also discernible in Table 3. These are: the husband wants no more children but the wife wants more (Column I) and the wife wants no more children but the husband wants more (Column 3). The country with the least disagreement (sum of Columns I and 3) is Niger where only $9 \%$ of couples are in disagreement while Namibia recorded the highest proportion (35\%) of couples with any form of disagreement.

With the exception of Malawi and Rwanda (where the proportion of couples in which the spouses disagree are about equal for both types of disagreement), the more prominent form of disagreement about fertility intentions is of the second type, where the wife wants no more children, but the husband wants more. Of all couples experiencing disagreement, the proportion in which the wife wants no more children but the husband does ranges from $48 \%$ in Rwanda to $85 \%$ in Guinea. Apart from Rwanda, the only other country where the proportion is $50 \%$ or less is Malawi. This lends credence to the claim that men want more children than their wives. The obvious implication of disagreement about future fertility intentions relates to how it affects subsequent contraceptive use and fertility behavior. The relationship between the joint distribution of husband and wife fertility intentions and use of contraception will be examined later.

Table 3 Columns 5 through 8 shows the levels of agreement and disagreement among monogamous couples with respect to partners' fertility intentions. Comparing Columns 2 and 6 in Tables 3 shows that the difference between monogamous couples and all couples with respect to the proportion of couples in which the partners agreed to stop childbearing is quite negligible. It ranges from 0 percentage point to $\mathrm{I} .4$ percentage points in Benin. With respect to agreement to continue childbearing we compared Columns 4 and 8 . This type of agreement is not as similar as the agreement to stop childbearing for monogamous couples compared to all couples, but difference is not substantial in most of the countries. The difference is $0-1$ percentage points in 17 of the 24 countries, $2-4$ percentage points in 5 countries (Benin, Guinea, Mali, Senegal and Uganda) and is highest (5.6 percentage points) in Burkina Faso.

28. This was derived by dividing Column 4 by the sum of Columns 2 and 4 , and multiplying the result by 100 . 
Timing of desired next child. Although substantial proportions of marital partners agree with respect to desired family size and fertility intentions, many couples in sub-Saharan Africa still have different reproductive goals. Even when spouses agree, there are still potential areas of conflict. For instance, agreement to stop having children may not translate into agreement to use contraception. Also, agreement to have another child does not imply agreement about the timing of the next birth.

In Table 4 we examined the preferred timing of the next birth among couples who want more children. A relevant question here is: Among couples who agree to have more children, does the husband want the next child sooner than the wife? Columns I and 2 present the results among all couples and show that the evidence is mixed on this issue. The proportion of couples who want more children in which husbands want $\mathrm{a}$ (nother) child sooner than wives ranges from $7 \%$ in Swaziland to $23 \%$ in Mozambique. Similarly, the proportion of these couples in which wives want $\mathrm{a}$ (nother) child sooner than the hus- bands is as low as $7 \%$ in Mozambique and as high as $20 \%$ in Namibia. Although husbands generally tend to want a(nother) child sooner than wives, there is little or no difference (less than 5 percentage points) between the two proportions in the vast majority of the countries. In 6 of the 24 countries (Guinea, Liberia, Mali, Senegal, Mozambique and Uganda), the difference between the two proportions is 5 percentage points or more in favor of the husbands. At least for these 6 countries, it can be concluded that husbands want the next child sooner than their spouses. The results for monogamous couples (Table 4 Columns 3 and 4) are generally similar to those for all couples. Men in monogamous marriages tend to want another child sooner than their spouses in 15 of the 24 countries while the reverse is the case in the remaining 9. However, for many of these countries, the difference between the two proportions is quite small. It is 5 percentage points or more in favor of the husband in only four countries, all of which are also included in the group of countries for all couples (Guinea, Liberia, Mozambique and Uganda). 
Table 4 Timing of desired next birth among men and women who are in union or married, in 24 countries: DHS 2003-2009

\begin{tabular}{|c|c|c|c|c|}
\hline \multirow[t]{4}{*}{ Country } & \multicolumn{2}{|c|}{$\begin{array}{l}\text { Of all couples who want } \\
\text { more children: }\end{array}$} & \multicolumn{2}{|c|}{$\begin{array}{l}\text { Of all monogamous couples } \\
\text { who want more children: }\end{array}$} \\
\hline & $\begin{array}{c}\text { \% husband } \\
\text { only }\end{array}$ & \% wife only & $\begin{array}{c}\text { \% husband } \\
\text { only }\end{array}$ & $\%$ wife only \\
\hline & wants soon & wants soon & wants soon & wants soon \\
\hline & (I) & $(2)$ & $(3)$ & $(4)$ \\
\hline \multicolumn{5}{|l|}{ Western/Central Africa } \\
\hline Benin & 15.0 & 12.0 & 13.4 & 9.1 \\
\hline Burkina Faso & 14.4 & 10.5 & 11.9 & 8.1 \\
\hline Chad & 17.9 & 15.8 & 16.8 & 11.9 \\
\hline Congo Democratic Republic & 10.9 & 10.1 & 9.6 & 8.5 \\
\hline Ghana & 10.6 & 11.2 & 10.0 & 10.5 \\
\hline Guinea & 22.2 & 11.0 & 16.6 & 11.5 \\
\hline Liberia & 20.9 & 12.1 & 19.7 & 11.3 \\
\hline Mali & 20.5 & 15.9 & 18.5 & 14.3 \\
\hline Niger & 18.5 & 15.6 & 16.3 & 14.2 \\
\hline Nigeria & 16.4 & 19.1 & 15.3 & 18.0 \\
\hline Senegal & 17.8 & 12.6 & 13.7 & 12.0 \\
\hline \multicolumn{5}{|l|}{ Eastern/Southern Africa } \\
\hline Ethiopia & 12.2 & 12.3 & 11.9 & 11.9 \\
\hline Kenya & 12.6 & 13.9 & 11.4 & 13.9 \\
\hline Lesotho & 9.3 & 8.5 & 9.1 & 8.5 \\
\hline Madagascar & 9.9 & 6.5 & 9.7 & 6.6 \\
\hline Malawi & 10.0 & 14.0 & 10.4 & 13.1 \\
\hline Mozambique & 22.9 & 16.0 & 23.0 & 15.8 \\
\hline Namibia & 18.4 & 20.4 & 18.3 & 20.1 \\
\hline Rwanda & 7.9 & 11.8 & 7.9 & 11.4 \\
\hline Swaziland & 7.4 & 10.7 & 6.8 & 10.8 \\
\hline Tanzania & 13.1 & 13.9 & 12.2 & 13.0 \\
\hline Uganda & 17.0 & 11.7 & 16.6 & 11.8 \\
\hline Zambia & 11.5 & 10.0 & 11.1 & 9.7 \\
\hline Zimbabwe & 10.2 & 12.4 & 9.6 & 12.8 \\
\hline
\end{tabular}




\section{Contraceptive behavior}

Few studies have examined contraceptive knowledge and use among men in sub-Saharan Africa, although the number is on the increase with increased attention to the role of men in fertility decision making. These studies have documented that a substantial proportion of men know at least one method, but in many countries only a small proportion are actually using contraception. Some of these studies have also pointed to the fact that husbands are more likely to report higher use of methods of family planning than their wives. ${ }^{29}$ An attempt to explain this finding identified a set of factors (multiple sexual partnership, differential reporting of use of the condom by husbands and wives, differences in perception of rhythm among marital partners, and the presence of adults during wives' interview) that may account for the difference. ${ }^{30}$ It has also been suggested that this finding may be related to the type of method used (e.g. condom), the frequency of use and/or the reference period. Thus, a man who used the condom once with his wife last week may report current use of condom while the wife who might have forgotten about that one incident or recalls several acts of unprotected intercourse they have had since then may report that no method is being used. ${ }^{31}$ In this section, we examine current use of contracep- tion by husbands and wives in the 24 countries.

Current use of modern contraception. Every respondent who reported knowing at least one method of family planning and she or the wife (in the case of male respondents) is not currently pregnant is asked if he/she is currently using a method. ${ }^{32}$ If he/she is using more than one method, the interviewer is instructed to record the most effective of the methods mentioned. Columns I through 3 of Table 5 present the joint distribution of husbands' and wives' reports of current use of modern contraception among all couples. The results show large variations in the use of modern contraceptive across countries for both husbands (sum of Columns I and 2) and for wives (sum of Columns 2 and 3 ). The percent using a modern method among husbands is lowest in Chad (4\%) and highest in Zimbabwe (69\%). Among wives, the percent ranges from $1 \%$ in Chad to $61 \%$ in Zimbabwe. Although there has been an improvement in contraceptive use in the region, use of modern methods remains low in much of sub-Saharan Africa. Only in four countries, Namibia, Swaziland, Zambia and Zimbabwe, all in Southern Africa, is this proportion $30 \%$ or more among husbands. Among wives, the proportion using modern methods is $30 \%$ or more in 6 countries, Kenya, Lesotho, Malawi, Namibia, Swaziland and Zimbabwe.

29. United Nations. 1995. Men's and Women's contraceptive practices. Population Newsletter, No. 59:9-13.

30. Ezeh, A.C. and G. Mboup.1997. Estimates and Explanation of Gender Differentials in Contraceptive Prevalence Rates, Studies in Family Planning, 28(2): I04-I 2 I.

31. Becker, Stan. 1996. Couples and Reproductive Health: A Review of Couple Studies. Studies in Family Planning 27(6): 29I-306.

32. The DHS question asked of men and women to elicit information on current use of contraception is: "Are you doing something now or using any method with any partner to delay or avoid pregnancy?". 


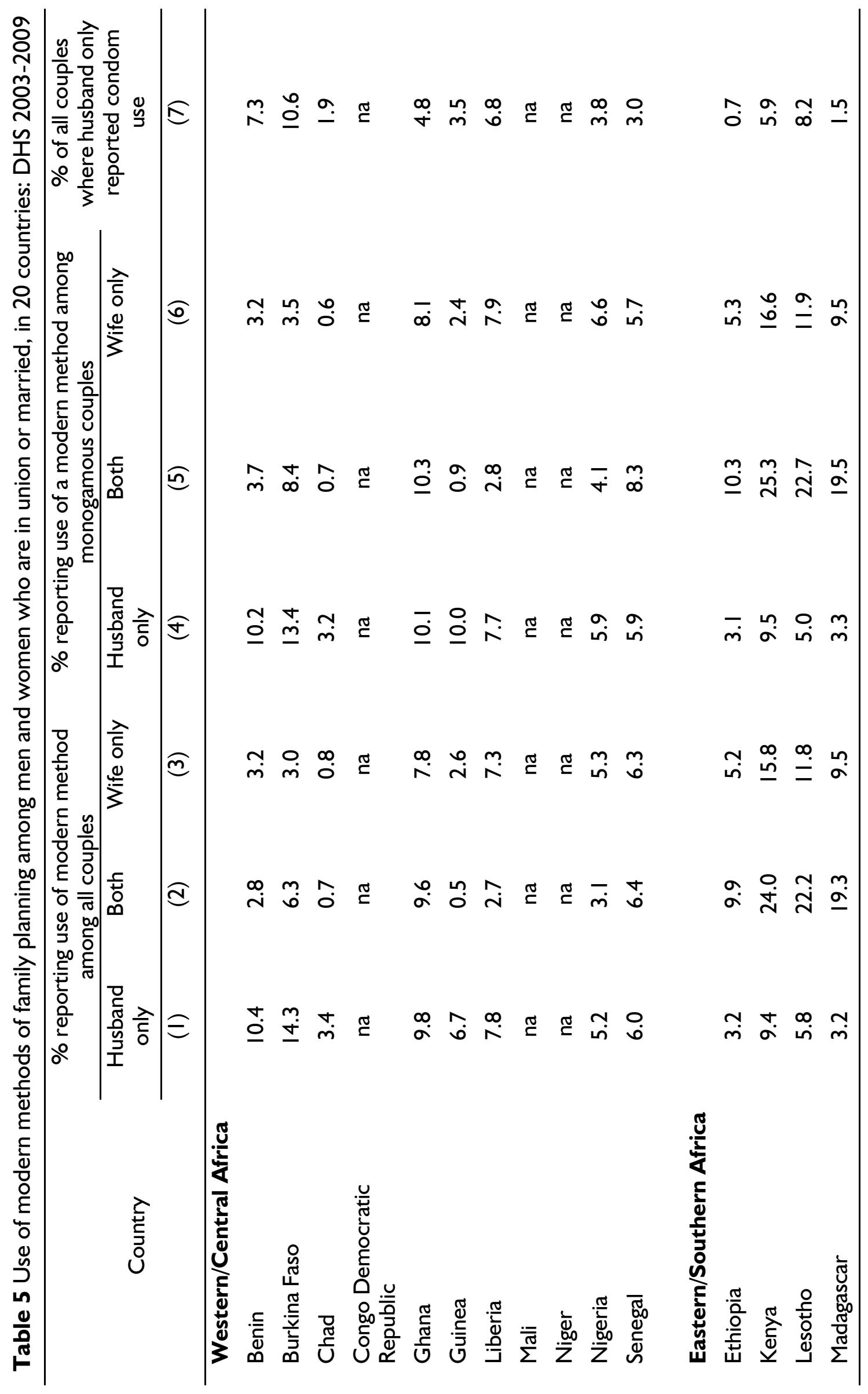




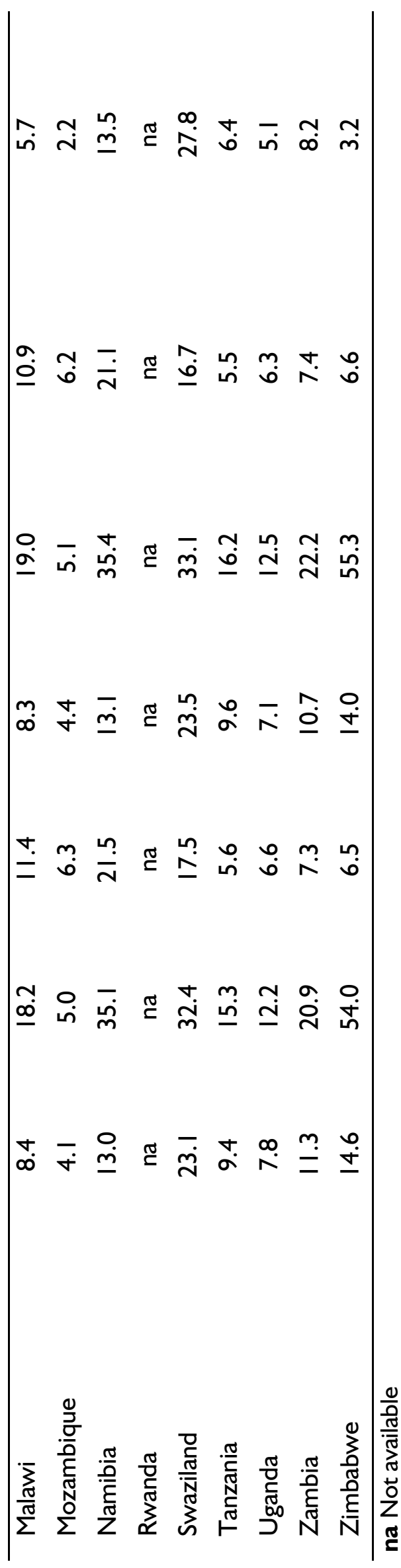

A comparison of the level of modern contraceptive use reported by husbands and wives in this study suggests that the differential reporting by sex is lower than commonly found in this earlier studies. Only in 6 of the 20 countries for which data exist are the reports of husbands and wives different by 5 percentage points or more. This means that husbands and wives are more or less in agreement with respect to their contraceptive use in about 2 out of 3 countries. However, as found in earlier studies when husbands and wives substantially disagree with respect to their use of modern contraception, it is often the case that husbands report more use of modern methods. Among the 6 countries where the reports of spouses are 5 percentage points or more different, husbands' reports are higher in 4 - Benin, Burkina Faso, Guinea and Zimbabwe - while the wives reports are higher in two Lesotho and Namibia.

Depending on whose reporting is taken into account, the estimated level of use of modern contraception can vary, sometimes substantially. If we focus on cases where both spouses report current use, the level of use is considerably lower in many countries than if wives' reporting alone is considered. However, if we focus on cases where at least one spouse reports current use of a method, the level of modern contraceptive use is considerably higher than if only one spouse's reporting is taken into account. For instance in Ghana, current use of modern methods is reported by $19 \%$ of husbands and $17 \%$ of wives, while both spouses report use in 10\% of the couples and at least one spouse reports use of modern 
methods in $27 \%$ of couples. Similarly, in Kenya, the level of current use is $33 \%$ among husbands, $40 \%$ among wives, $24 \%$ when both spouses report use and $49 \%$ when either spouse reports use. In Benin, the use of modern methods among couples when either spouse reports use is more than quadruple the level when both spouses report use and more than double wives only reporting of use. It is apparent from these examples that differences in the reporting of current use of modern contraception between husbands and wives can be substantial in sub-Saharan Africa. But as noted above, the differential reporting is not as large as found in some earlier studies. Nevertheless, where these differences exist, the reason is not clearly evident.

We also examined current use of contraception among monogamous couples to explore whether the reporting of method use among them is different than what was observed for all couples (Table 5 Columns 4 through 6). The results show little or no difference in spousal reporting of current use of contraception among monogamous couples as compared to all couples. For example, the difference between the proportions of monogamous couples and all couples in which the spouses agreed that they were using modern methods is very negligible. Out of the countries for which data are available, that difference is less than I percentage point in 14 countries and between I and 2 percentage points in the remaining six countries. Similar magnitudes of differences are observed when one compares the proportions of monoga- mous and all couples in which the husband only or the wife only reported current use of contraception.

Current use of the condom. It is often claimed that differential reporting of condom use may explain the difference, since husbands often report higher use than wives. ${ }^{33}$ The argument is that since women are not the ones who actually use the method, they may fail to report its use. So, the question is, is condom use the source of the differences in husbands' and wives' reporting of modern contraceptive use? If this were the case, we would expect substantially larger proportions of husbands to report condom use than their spouses. We examine this by looking at the percentage of couples in which only the husband reports condom use (Table 5 Column 7). Our finding shows that this may be an important explanation for the discrepancy. The percentage ranges from $0.7 \%$ in Ethiopia to $28 \%$ in Swaziland. The significance of this differential reporting of condom use to explaining the disparity between husbands' and wives' reporting of current use of modern methods can be seen by relating Column I with Column 7 of Table 5. Among couples where only the husband reports use of modern method, the proportion that is due to husbands' reporting of condom use ranges from $22 \%$ in Zimbabwe to $143 \%$ in Lesotho. This ratio is more than one half in 15 of the 20 countries. While some other factors may contribute to the observed differences between husbands' and wives' reporting of use of modern contraception, the role of condom use reporting seems to

33. De Walque, D. and R. Kline. 20I I. Variations in Condom Use by Type of Partner in I3 Sub-Saharan African Countries, Studies in Family Planning, 42(I): I-I0. 
be very important and deserves further examination.

But these findings also add another dimension to the issue of differential reporting between husbands and wives that has not been given previous consideration. That is that wives may be reporting use of some methods that husbands are not reporting. For example, in three countries, Lesotho, Namibia and Swaziland, the ratio of the proportion of husbands who only reported condom use to the proportion of husbands who only reported use of modern methods is higher than $100 \%$ (102-143\%). This suggests that wives in these countries were reporting use of other methods that the husbands were not reporting. Also, in Lesotho, Malawi and Namibia, despite the fact that the proportion of only husbands reporting condom use is $5 \%$ or higher, the proportions of only wives reporting use are higher than the proportions of only husbands reporting use. In 6 additional countries, Ghana, Liberia, Nigeria, Tanzania, Uganda and Zambia, the difference between the two proportions is less than 5 percentage points, although the proportion of husband only reporting condom use is 5 percent or more, Whatever the explanation, these discrepancies also emphasize the importance of obtaining information from both men and women when measuring contraceptive prevalence.

\section{Fertility intentions and contraceptive behavior}

We have shown that husbands and wives do not necessarily have the same fertility preferences and that they may differ in their reporting of contraceptive use. Since fertility and contraceptive outcomes for a couple requires the involvement of both partners, each spouse's attitudes and preferences as well as attitudinal agreements between the spouses are often viewed as vital in shaping actual behavior. As noted earlier, it has been established that fertility intentions, both in terms of individual spouses' preferences as well as joint preferences of spouses, predict subsequent fertility behavior. ${ }^{34}$ The issue that needs further investigation is the relative importance of individual spouses' preferences in determining reproductive outcomes in sub-Saharan Africa.

In this section we examine the relationship between fertility intentions and current use of contraception. The idea is to determine how individual and joint future fertility preferences translate into contraceptive use. In this respect, we start with the assumption that when an individual wants no more children or wishes to postpone childbearing he/she will be using contraception. Under this assumption, it is easy to see why contraceptive use will be high when both spouses want to stop or postpone childbearing and low when they both want to have another child. It is, however, more interesting and important to find out whether and to what extent contraception is used in situations where spouses disagree about their intentions. Do couples use contraception more when the husband wants more children and the wife does not or when the wife wants more and the husband does not? Is it true that where

34. Bongaarts, John I99I, op. cit. (see reference 22); Thomson E, McDonald E and Bumpass LL, 1993, op. cit. (see reference 22). 
men are favored in terms of access to household and community resource and recognition, they also have a greater influence on reproductive outcome? This analysis will help to shed light on the issue of whose view is more influential in fertility-decision-making. The results of this analysis are presented in Table 6. For each country, the first row shows the level of use of modern contraception among monogamous couples by joint fertility intentions without controlling for the effects of any other variable (i.e. unadjusted proportion). The findings in the first row largely support the a-priori assumed direction of method use among couples who are in agreement. With the exception of Benin, Burkina Faso, Chad and Nigeria (all in West Africa), use of modern contraception is highest when both spouses agree to stop childbearing. The unadjusted percentage of couples in this category who are using modern methods ranges from $6 \%$ in Chad to $75 \%$ in Zimbabwe (Column 2). More than $20 \%$ of these couples are using modern methods in 18 of the 23 countries for which data are available. On the other hand, use of modern contraception is lowest among couples who agree to have more children in most of the countries. The level of use of modern methods for this group of couples ranges from $2 \%$ in Chad to $69 \%$ in Zimbabwe: it is less than $20 \%$ in 12 countries (Column 5) Apparently, these couples are using in order to postpone the birth of another child. Under both situations of agreement, couples in Eastern and Southern Africa are more likely to be using contraception than their counterparts in Western and
Southern regions.

When there is a disagreement between spouses about their fertility intentions there is no clear pattern with respect to the direction of contraceptive use (Columns 3 and 4 ). $\ln 13$ of the 23 countries, use of modern contraception is higher in magnitude when the husband only wants to stop childbearing. In the other 10 countries, however, use of a modern method is higher when it is the wife only who wants to stop having children. The magnitude of the difference in use according to which spouse wants more or wants no more children suggests, however, that the difference is trivial in about half of these countries: it is less than 8 percentage points in 16 of the 23 countries. For the remaining 6 countries, the difference ranges from 10 percentage points in Mali to 21 percentage points in Madagascar, and use is higher when the husband only wants no more children in 4 of these 6 countries. ${ }^{35}$ These findings suggest that although there is no systematic difference, and no simple generalization, there is a tendency to greater influence of husbands' preferences on contraceptive use in sub-Saharan Africa. There is no notable difference between Western and Central African countries and the countries in Eastern and Southern parts of the region. This conclusion is supported by the male dominance hypothesis that is often associated with the traditional sub-Saharan cultural norms and social systems. Is this conclusion valid after controlling for the effects of other variables? This question is examined below.

35. The six countries are Benin, Burkina Faso, Mali, Malawl, Madagascar and Zambia. 


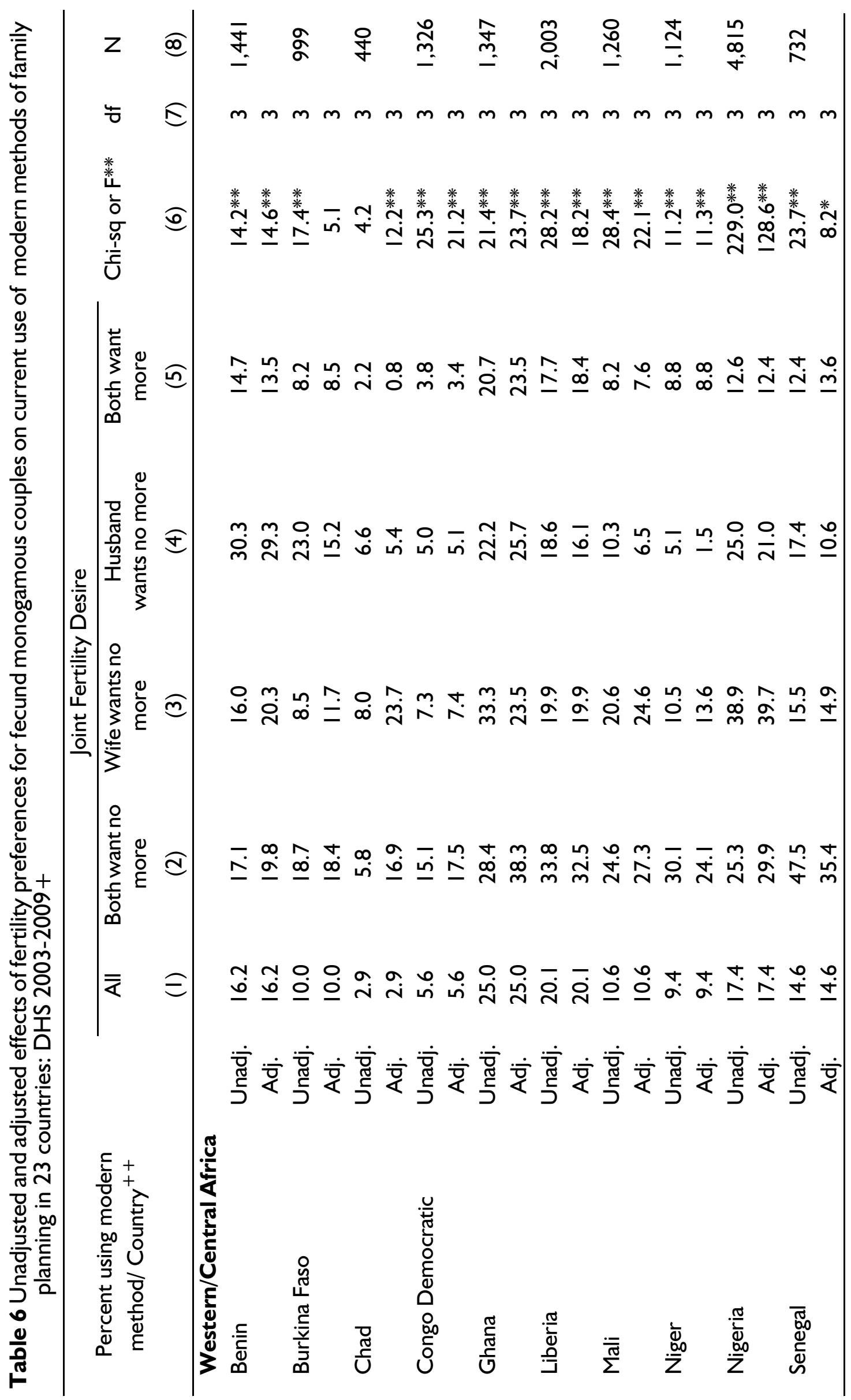




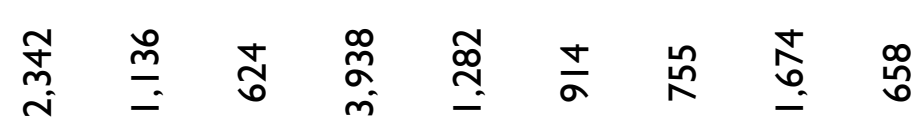
$m m m m m m m m m m m n m m m$

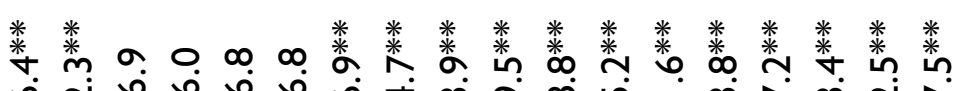

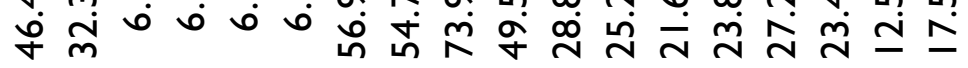

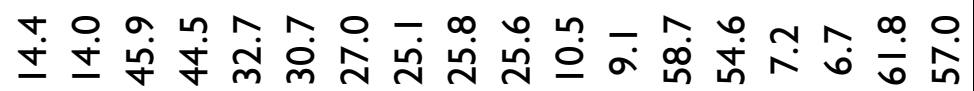

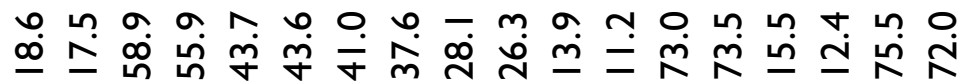

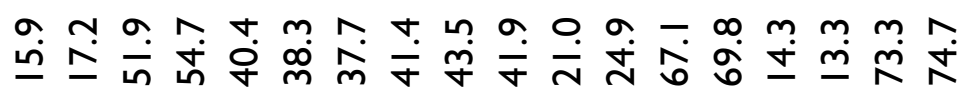

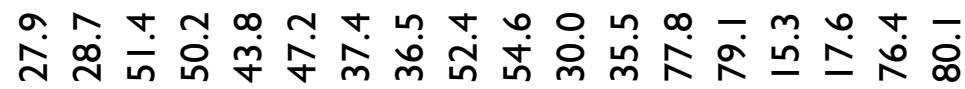
이일

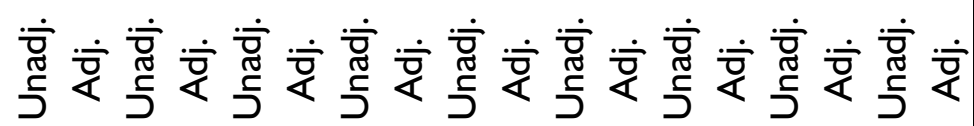




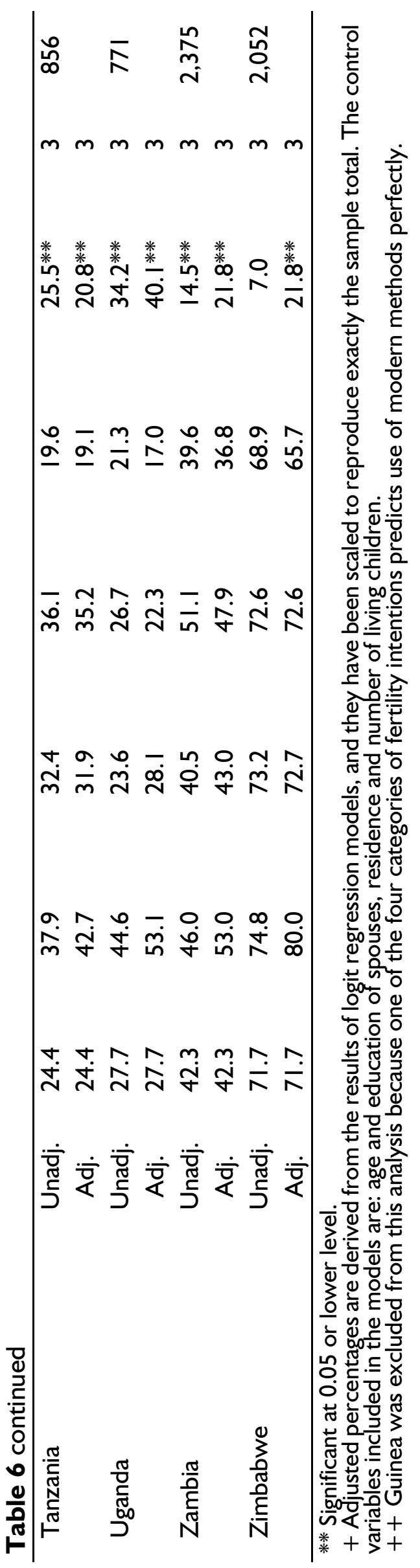

The second row of Table 6 for each of the 23 countries for which this analysis is possible presents the corresponding level of use of modern methods by joint fertility intentions after controlling for the effects of the age and education of both spouses, residence, and the number of living children, in logistic regression models. Judging from the chi-square values and the associated degrees of freedom in Columns 6 and 7 , the joint fertility intentions of couples emerges as a significant predictor of current use of modern methods in 20 of the 23 countries analyzed. ${ }^{36}$

For 16 countries, the pattern and the direction of the relationship between the two variables of interest remain largely similar to the ones observed before controlling for the effects of those other variables for couples who agree. In II of them, use of modern methods is highest when both spouses want to stop childbearing and lowest when they want to have more children. Comparing the adjusted proportions in Columns 3 and 4 (second row) for the 20 countries where the preference variable remains significant after controlling for the effects of other factors, and assuming a difference of 5 percentage point or more as substantial, only in Benin and Namibia are couples more likely to be using modern methods of family planning when the husband wants no more children and the wife wants more. On the other hand, use of modern contraception is higher among couples in Chad, Mali,

36. The variable loses its significance (at $5 \%$ level) as a predictor of use of modern contraception after controlling for the effects of other variables in Burkina Faso, Kenya and Lesotho. 
Niger, Nigeria, Malawi, Mozambique, and Uganda when the wife wants no more children and the husband does. The results for the remaining I I countries show very similar levels of use in the two groups of couples, that is, when either partner wants no more children they are equally likely to use modern methods. Thus, compared with the situation before introducing the controls, the general pattern of little or no difference in contraceptive use among couples when the spouses disagree about whether or not they want another child still holds. However, among the 9 countries where there are significant differences in use by gender preference, the results suggest that the preference of the wife appears to be more dominant in determining whether or not the couple use modern contraception in the majority of these countries ( 7 compared to 2 ) when the effects of other variables are taken into account. Thus, the conclusion is that in general, there is little or no difference in contraceptive use among couples by differential reporting of fertility preference between spouses in sub-Saharan Africa. When there is a difference, the wife's preference seems to predominate in predicting contraceptive use.

\section{Discussion}

The findings from this study indicate that in many countries in sub-Saharan Africa, both husbands and wives want a large family. An examination of the subject at the level of couples shows a pattern as observed at the aggregate level. In many of the 24 countries included in this study, there is a substantial discrepancy between the preferences of spouses: in about two-thirds of the countries, husbands and wives differ by one child or more in the family size they consider ideal. Our analysis also shows that husbands want a larger family size than their wives in most of the 24 countries included in this study. The disparity is particularly pronounced in Western and Central Africa: in countries included from these sub-regions, husbands want I-5 children more than their wives. These findings suggest, therefore, that husbands and wives in sub-Saharan Africa do differ in their fertility goals, although the magnitude of the differences as well as its significance for behavior varies across countries and sub-regions.

With regard to fertility intentions, husbands and wives for the most part agree about whether or not they want more children in all of the 24 countries. Two-thirds or more of the couples are in agreement on this subject with generally little variation by country. However, in $9 \%$ to $35 \%$ of couples, partners disagree about whether they want another child. Disagreement is usually of the type whereby the husband wants more children but the wife does not. Our analysis also shows that when marital partners agree to have another child, they may differ about the timing of the next child: whether they want the child now/soon (within two years) or later. This type of disagreement occurs in $18 \%$ to $39 \%$ of these couples, and more often husbands want to have the next child sooner than do their wives. Again, this evidence of greater motivation to have children among husbands than wives is more prevalent in Western and Central Africa compared to the Eastern and Southern parts, where the proportions of couples 
in which husbands want a(nother) child sooner is similar to the proportion in which wives do.

The findings from the two indicators of reproductive preferences examined in this paper have implications for fertility and family planning behavior. First, they show that decline in family size preferences, which is a necessary precursor of decline in actual fertility, tends to occur first among wives. Furthermore, the results indicate that married women probably have a better understanding of the benefit of spacing their children and the danger associated with having births in quick succession than their husbands. It follows, therefore, that the use of contraception either to space births or to limit family size is likely to be initiated by wives rather than their husbands. But success of achieving a smaller family size will depend on how responsive husbands' fertility preferences are to the changes in their spouses' preferences and the influence of husbands' preferences on couples' reproductive behavior. As noted earlier, studies have shown that husband's opposition to family planning, presumably because of their greater desires for large family, is often a deterrent to women's use of contraception. In some cases, women who are strongly motivated to limit their family size may be using a method without the knowledge of their spouses.

Contraceptive knowledge is high among husbands and wives in the 24 countries and only small differences are observed between the reporting of marital partners. On the other hand, results from our analysis show some evidence of substantial differences between husbands' and wives' report- ing of use of modern methods of contraception. It is important to note however, that the differences are not as substantial as found about 10 years ago when a similar analysis was conducted. This tendency towards agreement in spousal reporting of contraceptive use is probably associated, at least in part, to increasing tolerance for family planning in the region and better communications among couples with respect to fertility related behaviors. The findings support the claim that husbands are more likely to report higher use of family planning than their wives.

While differential reporting of condom use between marital partners seems to be an important source of this discrepancy in spousal reporting of contraceptive use, it does not appear to be the sole cause. As a matter of fact, even in countries where the proportion of couples in which husbands only reported condom use is fairly substantial, women still reported more use of modern contraception than husbands. This may mean that either husbands are not aware that their wives are using a modern method, or just as some women are assumed to do in the case of condoms, some men are not reporting female methods that their wives are using. This finding highlights a potential problem associated with the conventional measure of contraceptive prevalence based only on women's report. Our results show that estimates of contraceptive use may vary widely depending on whether the researcher relies solely on data obtained from women or takes into account husbands' reporting of use by interviewing both partners. For instance in Benin, husbands' reporting of use of modern method is twice as 
high as their wives' reporting. More research is needed on the causes of this discrepancy, but at the same time, studies of fertility and family planning will benefit from adopting measures of contraceptive use that are based on the reporting of both partners.

Our findings support the claim that reproductive intentions are important predictors of contraceptive behavior. Before controlling for other variables, the joint fertility intentions of the spouses significantly determines whether or not the couple will use modern methods of family planning in 19 of the 23 countries for which we have information. After controlling for the effects of spouses' characteristics, the joint fertility intentions also emerge as a significant predictor of use of modern contraception in 20 of the 23 countries. As expected, couples generally tend to use contraception more when they want to stop childbearing and less when they intend to have more children even in countries where the level of use is still low. The more interesting investigation, however, relates to the level of contraceptive use when couples disagree about their intentions: when one spouse wants more but the other does not. This issue is not easy to resolve.

Overall, the results of the multivariate analysis suggest that in the majority of the countries in sub-Saharan Africa, the preferences of both partners are about equally important in predicting a couple's use of modern methods. However, in situations where the influence of the partners' preferences on modern contraceptive use differs, the wife's preference exerts a stronger influence on the couple's contraceptive behavior in 7 of the 9 countries where the impacts of the spouses' preferences on modern contraceptive behavior are significantly different. Comparing these findings to the results of a similar analysis conducted about a decade ago suggests that not much has changed in terms of the pattern and direction of the effects of spousal fertility preference disagreement on contraceptive use. ${ }^{37}$ In both studies, when this disagreement matters in terms of its predictive power with respect to use of modern methods, wives desires tend to predominate over those of husbands. This does not seem to follow the conventional wisdom that arrogates power and authority to the male partner in the marital dyad. If it is true that men have more power than their wives in household decision-making, that power does not seem to drive contraceptive use among couples in favor of the husband's fertility preference. There is need for more in-depth research to help understand the factors that are associated with women's ability to meet their contraceptive needs and take control of their own health. At the same time, to ensure open and sustained use of contraception within union, family planning programs must continue to involve men by helping them to understand the importance of fewer and well spaced births for the health of women and their children.

37. Bankole, A. and S. Singh. 1998. Couples fertility and contraceptive decision making in developing countries: Hearing the man's voice, International Family Planning Perspectives, $24(1): 15-24$ 